原著

\title{
造影剤アレルギーを有する脳血管障害患者に対する直達手術
}

\author{
堤圭治, 堀内 哲吉, 本郷 一博
}

\section{Direct Surgery for Cerebrovascular Disease in Patients with Iodine Allergy}

\author{
Keiji Tsutsumi, M.D., Tetsuyoshi Horiuchi, M.D., and Kazuhiro Hongo, M.D. \\ Department of Neurosurgery, Shinshu University School of Medicine, Matsumoto, Nagano, Japan
}

\begin{abstract}
Summary: In the field of vascular surgery, contrast-enhanced imaging using iodinated contrast media (ICM) is essential in determining the diagnosis and therapeutic strategy. However, in a few patients, contrast-enhanced imaging is contraindicated because of hypersensitivity against ICM or thyroid disease. We present two cases of direct surgery for cerebrovascular disease without using ICM in the preoperative evaluation. The first case was that of a 72-year-old woman who had a history of moderate allergy to ICM. She had transient weakness of the right upper extremity. Magnetic resonance (MR) images showed left intracranial internal carotid artery stenosis and multiple cerebral infarctions. Her symptom persisted despite antiplatelet therapy, and follow-up MR images revealed aggravation of the left-sided cerebral infarction. We performed left superficial temporal artery-middle cerebral artery anastomosis. After the operation, her symptoms disappeared. The second case was that of a 71-yearold woman with a history of severe ICM allergy. She presented with right-sided weakness, and MR images showed left internal carotid artery bifurcation stenosis. She underwent carotid endarterectomy for the prevention of recurrent cerebral infarction. We could perform treatment on schedule and found no perioperative complication in the 2 cases. By using multimodality evaluations, we could perform safe and secure surgery in the patients with hypersensitivity against ICM. Tailor-made decision on whether direct surgery should be performed with or without contrast medium examination is necessary for patients with hypersensitivity against ICM.
\end{abstract}

\section{はじめに}

世界中で，年間に 7,000 万人以上がヨード造影剤を使用 した画像診断検査を受けている て, ヨード造影剤を用いた画像検査は, 診断および治療方 法の決定に重要な検査である。一方, ヨードまたはヨード 造影剂に対して過敏症の既往がある患者や, 重篤な甲状腺 疾患を有する患者にはヨード造影剂の使用は禁忌であ

\author{
Key words: \\ - iodinated contrast media \\ - allergy \\ · hypersensitivity \\ - gadolinium \\ $\cdot$ multimodality
}

Surg Cereb Stroke (Jpn) 45: 115-120, 2017

信州大学 脳神経外科(受稿日 2016. 8. 30) (脱稿日 2016. 12. 16)〔連絡先： ₹ 390-8621 長野県松本市旭 3-1-1 信州大学 脳神経外科 堤 圭治] [Address correspondence: Keiji Tsutsumi, M.D., Department of Neurosurgery, Shinshu University School of Medicine, 3-1-1 Asahi, Matsumoto, Nagano 390-8621, Japan] 


\section{対象と方法}

2014 年 1 月から 2015 年 9 月の間に, 信州大学医学部附 属病院で直達手術を施行した脳血管障害の患者 81 名 81 症 例を対象とした。

ヨード造影剤の使用の可否は，院内のプロトコールに のっとり, 造影剂アレルギーの既往, 推算系球体滤過值 (estimated glomerular filtration rate : eGFR)による腎機 能評価, 気管支喘息の既往, 甲状腺疾患の有無に基づ き，個々に判断した，造影剂アレルギーの既往は，患者本 人および家族からの問診や電子カルテの情報を参照し た。過去に中等度, 重度の造影剂副作用を有する患者, eGFR が $30 \mathrm{ml} / \mathrm{min} / 1.73 \mathrm{~m}^{2}$ 未満の患者, 気管支喘息の症 状が薬物によりコントロールされていない患者, 明らかな 甲状腺機能充進症を有する患者には，原則としてヨード造 影剂検査が不適応と判断した。

\section{結果}

全 81 例の手術の内訳は, 50 例が開頭クリッピング術, 7 例が頭蓋外-頭蓋内血管バイパス術，24 例が頚動脈内膜 剝離術であった、ヨード造影剂検査が不適応と判断された 患者は 2 名であり，それぞれ頭蓋外一頭蓋内血管バイパス 術が 1 例, 頚動脈内膜剝離術が 1 例であった。 1 例はヨー ド造影剂を使用した際に，全身性の尋麻疹を生じた既往が あり，中等度の副作用があったと判断された。もう 1 例 は，ヨード造影剂の使用により重度の副作用であるアナ フィラキシーショックを呈した既往があった。

\section{症例}

〈症例 1〉 72 歳, 女性.

右上肢の一過性の脱力発作を契機に MRI/A 検查で頭蓋 内左内䫋動脈狭窄と散在性の脳梗塞を指摘された (Fig. 1A， B， G)．既往症に高血圧，脂質異常症，糖尿病があり，軽 度の腎機能障害も伴っていた。また，ヨード造影剤の使用 により中等度の副作用である全身性の蕁麻疹を呈した既往 があった．画像診断後，抗血小板薬の内服による治療が継 続されたが，その後もたびたび右上肢の一過性の脱力発作 がみられ，また経時的な MRI 検查で左大脳半球の FLAIR (fluid attenuated inversion recovery) 高信号域の拡大がみ られた (Fig. 1C，D)。症候性の左頭蓋内内䅡動脈狭窄に対 し, 左浅側頭動脈一中大脳動脈吻合術を施行した。造影剂 過敏症の既往と軽度の腎機能障害を考慮し, 術前の精查は 造影剂を使用せずに MRI/A，単純 CT で行った，MRA で左内澒動脈 C2-3 の狭窄部位ならびに浅側頭動脈の開存 を確認した(Fig. 1G)。 MRAの元画像と単純 CT を対比 し，浅側頭動脈に石灰化のないことを確認した(Fig. 2A，
B)。また, 経皮的超音波ドプラ血流計測装置を用いて, 術前に浅側頭動脈の走行㧍よび血流を確認するととも に, 術後の血流評価も行った。周術期に合併症はなく経過 し, 術後の MRIで新規梗塞巣の出現はなくMRA で吻合 部の良好な開存を確認でき(Fig. 1E, F, H), 右上肢の脱力 発作も消失した。

〈症例 2〉 71 歳, 女性.

右上下肢の麻痺を主訴に近医を受診し，MRI/A 検査で 左大脳半球の散在性の脳梗塞と左頚部内頚動脈分岐部の狭 窄を指摘された Fig. 3A，B)。既往に高血圧, 脂質異常 症, 糖尿病, 狭心症, 腹部大動脈瘤, 右中大脳動脈瘤 (ク リッピング術後)があり，軽度の腎機能障害もみられた。 既往症によるヨード造影剂を用いた画像検査を頻回に施行 されているが, 最終検査の際にアナフィラキシーショック を呈した既往があった。頚動脈超音波検査では，狭窄部に 音響陰影を伴う高輝度の石灰化病変が一部認められ，ま た，狭窄部には広範に低輝度の領域がみられソフトプラー クの存在が示唆された(Fig. 3C). カラードプラでは乱流を 示唆するモザイクエコーを認め, 左内頝動脈狭窄部で計測 した収縮期最大血流速度は $358 \mathrm{~cm} / \mathrm{sec}$ であり, NASCET (The North American Symptomatic Carotid Endarterectomy Trial) 法で 70\%を超える高度狭窄が示唆された。

頭蓋内の主幹動脈は, 既往の右中大脳動脈瘤のクリップ によるアーチファクトで右中大脳動脈近位の評価は困難で あったが，今回の原因と考え得る狭窄は認められず(Fig. 3F), 症候性の左頚部内澒動脈狭窄と診断し, 頚動脈内膜 剥離術を計画し，造影剤を使用せずに MRI/A，単純 $\mathrm{CT}$, 頚動脈超音波検查により術前の評価を行った. MRI 検査では, 脂肪抑制画像, black blood image と MRAを 同期させ，また多断面再構成画像を利用してプラークの局 在, 性状を詳細に検討した。単純 CT では, 頚動脈超音波 検查所見とあわせて内頝動脈狭窄部外周に石灰化病変がみ られた。単純 CT, MRI，MRAの画像を同期させること により，頚動脈分岐部が $\mathrm{C} 4$ 椎体の高さにあり，プラーク の遠位端が C3 椎体レベルであることを確認した(Fig. 4).

また，造影剂を使用せず非侵襲的な arterial spin labelingにより脳血流の評価を行い, 左中大脳動脈領域が対側 に比べ脳血流が低下している所見を得た. 左頚動脈内膜剥 離術を施行し，良好な血管の拡張を得て(Fig. 3D，E)，そ の後，脳梗塞の再発はなく経過している.

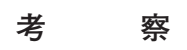

脳神経外科領域に限らず血管障害疾患において, 造影剂 を用いた画像検査は診断・治療法の決定において有用であ ることに異論の余地はない。一方，ヨード造影剤に過敏症 

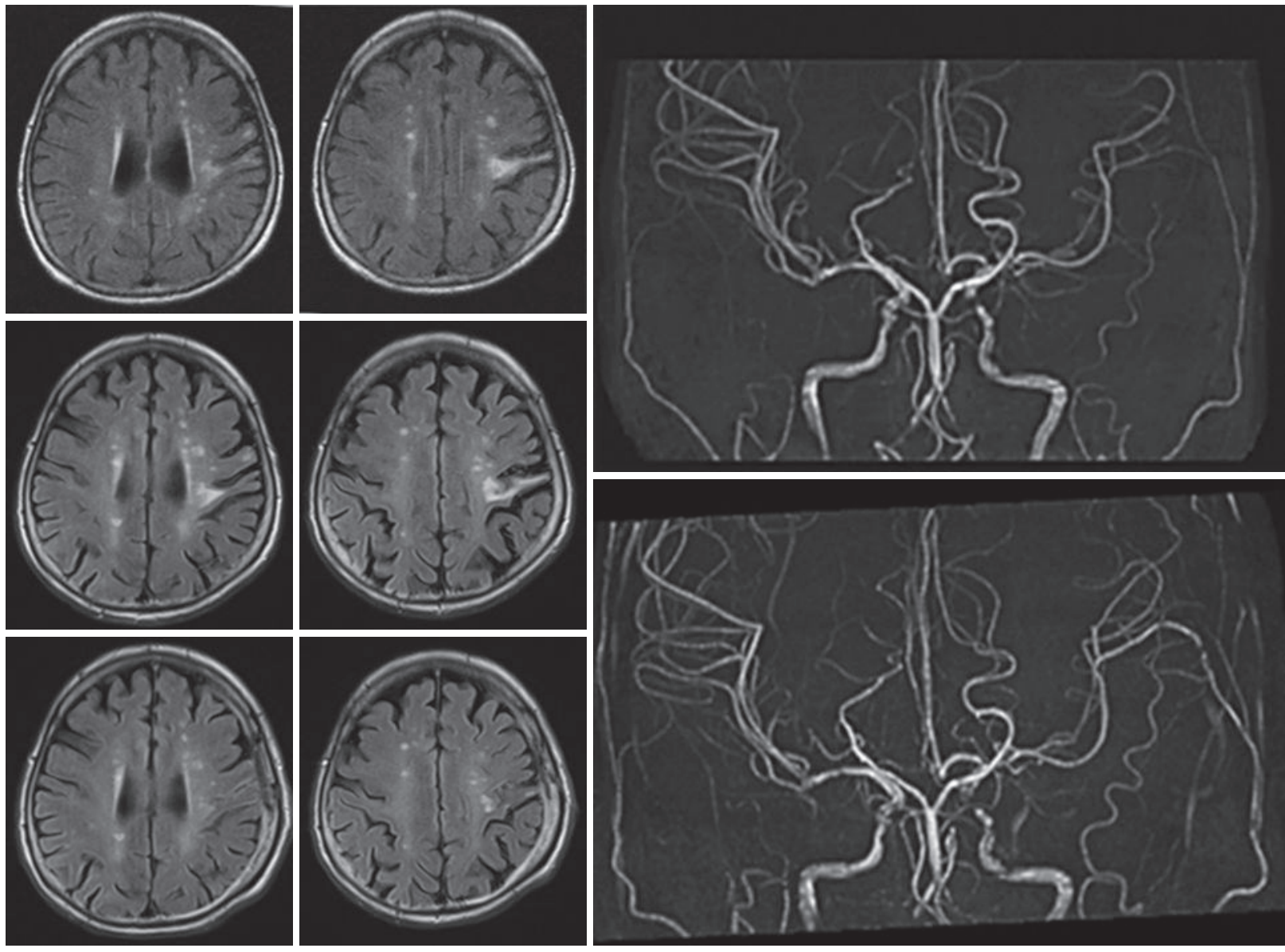

Fig. 1 Serial preoperative magnetic resonance (MR) fluid-attenuated inversion recovery (FLAIR)

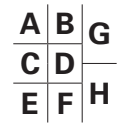
images showing aggravation of the left-sided FLAIR high intensities (A-D).

Preoperative MR angiogram showing left internal carotid artery stenosis at the C2-C3 portion $(\mathbf{G})$

Postoperative FLAIR images showing no new infarctions (E, F).

Postoperative MR angiogram showing patency of the left superficial temporal and middle cerebral arteries $\mathbf{( H )}$

を呈する患者が存在し，その診断や治療に苦慮することが ある. 非イオン性, 水溶性, 低浸透圧性のヨード造影剤の 出現により即時性の副作用の総数だけでなく, 重篤な副作 用の発生率は著明に低下したとされている214). しかし, 造影剤の改良によっても依然として0.01-0.04\%の確率で 重篤な副作用が起こり得ると報告されている2448). また, ヨードによるアレルギーは，その発生に閾值はなく非用量 依存性とされている ${ }^{10)}$.

ヨード造影剂にアレルギー歴のある患者に対する対応と しては，造影剤の使用を避け，代替手段による検査を施行 することが基本となる。また, 既往の副作用が軽度であっ た場合には, リスクとベネフィットを検討し, ベネフィッ トが上回ると判断された場合には，ステロイドや抗ヒス夕 ミンなどの前投薬を用いたうえで造影剤を使用することが
考慮される

もう 1 つの選択肢としては，ヨード造影剂以外の造影剂 を使用することである。ヨード造影剤の代替として代表的 なものはガドリニウム造影剤が挙げられ，他の血管領域に おいてもその使用報告があり，脳血管内治療に関する報告 も本邦からの報告を含め 4 件ある ${ }^{1319) 12}$. ガドリニウムの 利点は, ヨード造影剤に比べ副作用が圧倒的に少ないこと であり，重篤な副作用の発生頻度は 0.0002-0.001\%と報告 されている ${ }^{11)}$ 。ただし、ヨード造影剤にアレルギーの既往 がある患者の場合, 副作用の発現率が 3-4 倍になるとの報 告もあり ${ }^{1113)}$ ，一概に安全性が高いとはいえない。他方, ガドリニウムにはいくつかの欠点も知られている. その 1 つは, ヨード造影剂に比べ造影能が劣ることであり, 造影 能を補うために使用量が増加してしまうことに留意する必 

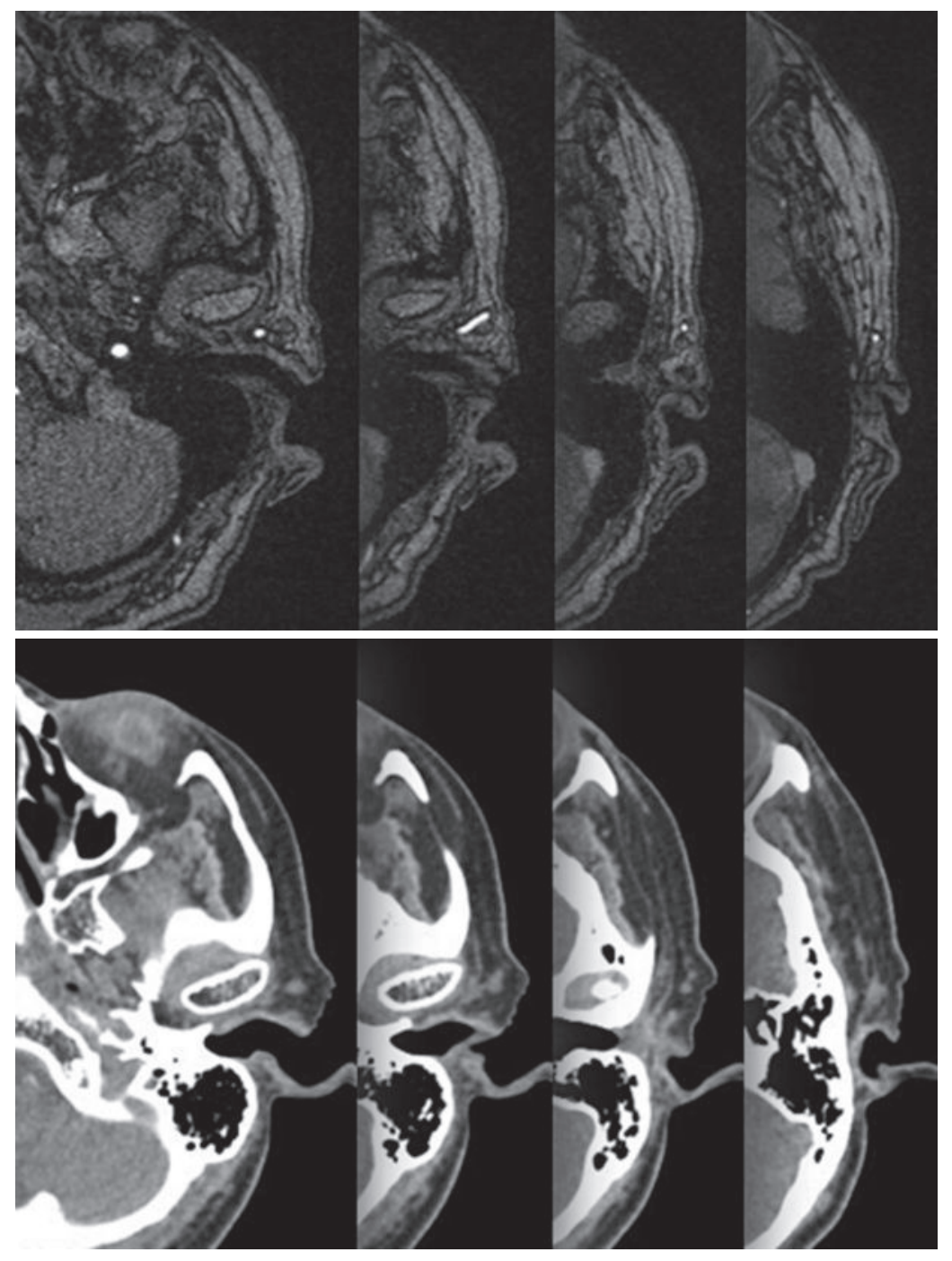

\section{$\frac{A}{B}$}

Fig. 2 Synchronized serial plain computed tomography (CT) images (A) and serial MR angiogram source images (B) showing no calcification of the left superficial temporal artery.

要がある。また，ガドリニウムと腎性全身性皮膚線維症 (neurogenic systemic fibrosis : NSF)の関係が指摘されて おり，特に腎機能低下患者への使用は慎重を期す必要があ る6).さらに，現在のところガドリニウムは血管撮影での 使用は保険適用になっていないことも認識しておく必要が ある。

造影剂を使用せずに，血管領域の治療を行った報告も散 見される。伊藤ら ${ }^{7}$ は造影剤を使用せずに血管内超音波を 用いて顤動脈ステント留置術を行った症例をまた Sakakibara ${ }^{11)}$ は血管内超音波のみで冠動脈ステント留 置術を施行した症例を報告している.

本報告では，ヨード造影剤のアレルギー歴を有し造影剂 の使用が不適応と判断した，頭蓋外-頭蓋内血管バイパス 術と頚動脈内膜剝離術の 2 症例を提示した. MRI/A， 単 純 CT，超音波検査を集学的に用いることで，十分な術前 評価と安全で確実な手術を施行し得た。非侵襲的な検査機
器や検査手法の向上により，現在では集学的に評価を行う ことでより多くの情報が得られるようになった，先述した 通り，ガドリニウム造影剂による副作用も一定の割合で生 じ得ることから, 緊急を要し代替治療のない interventional radiology では, ガドリニウムによる造影剤の代替の選 択も必要であるが, 直達手術に際しては, 他の診断法で同 等の情報が得られると判断される場合には, そちらを優先 するべきであると思われる。ただし, 脳動静脈奇形や硬膜 動静脈瘻の確定診断 - 術前評価や血管内治療が第一選択と なる内頝動脈海綿静脈洞㾇などの脳血管障害において は, 現時点では造影剤の使用が必須と考えられ，造影剤ア レルギーを有する患者の治療機会を一律に奪うことが好ま しくないとの観点から, 十分な説明と施設の体制を整備し たうえで，造影剤の使用を容認せざるを得ない場合もある. 

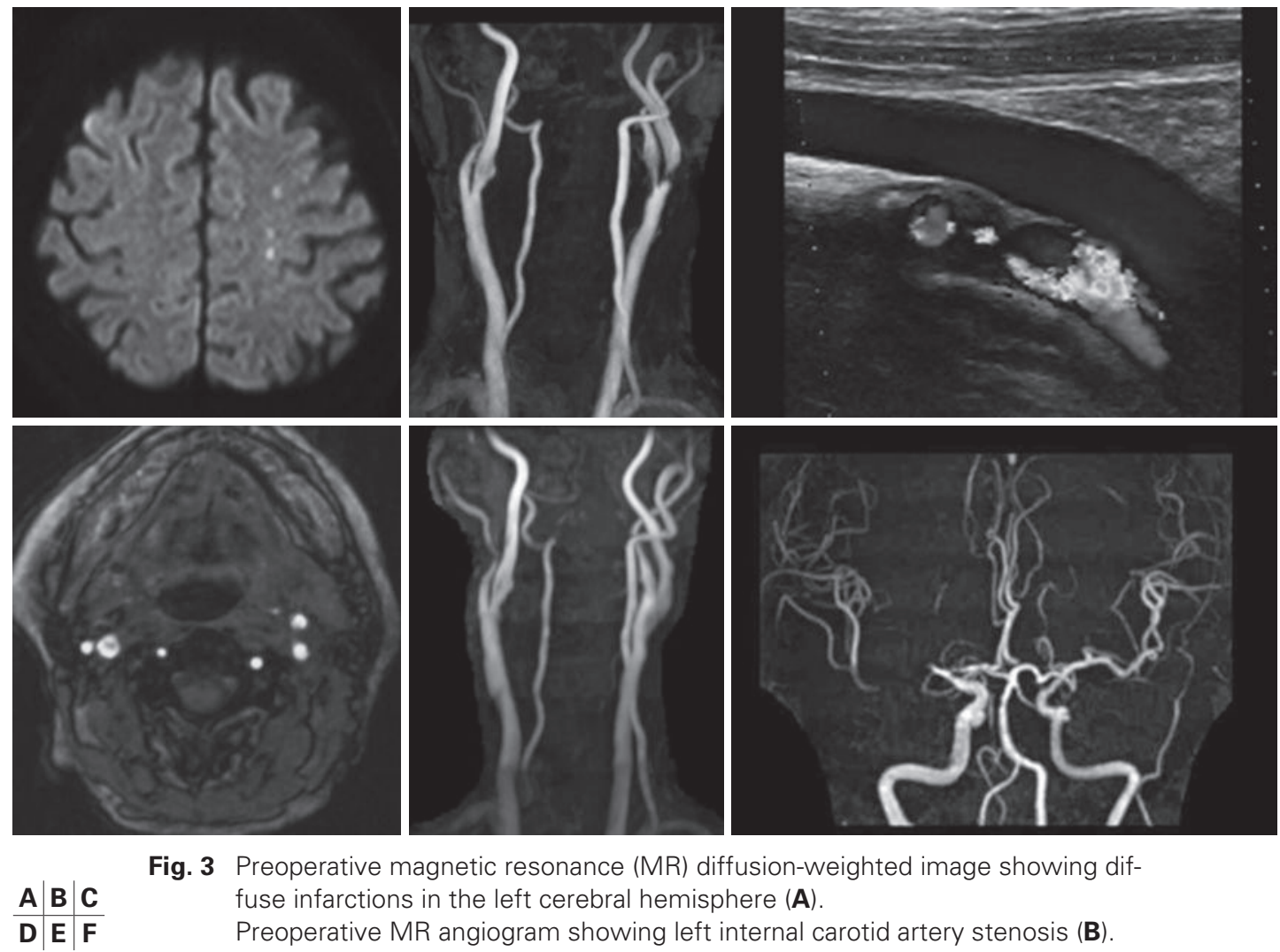

Fig. 3 Preoperative magnetic resonance (MR) diffusion-weighted image showing diffuse infarctions in the left cerebral hemisphere (A).

Preoperative MR angiogram showing left internal carotid artery stenosis (B).

Preoperative carotid ultrasonography image showing partial hyperechoic and diffuse hypoechoic lesions at the left internal carotid artery $(\mathbf{C})$.

Postoperative MR angiogram source image (D) and MR angiogram (E) showing patency of the left internal carotid artery.

Preoperative MR angiogram showing no major trunk stenosis of the intracranial arteries, excluding poor visualization due to the clip artifact of the right middle cerebral artery (F).
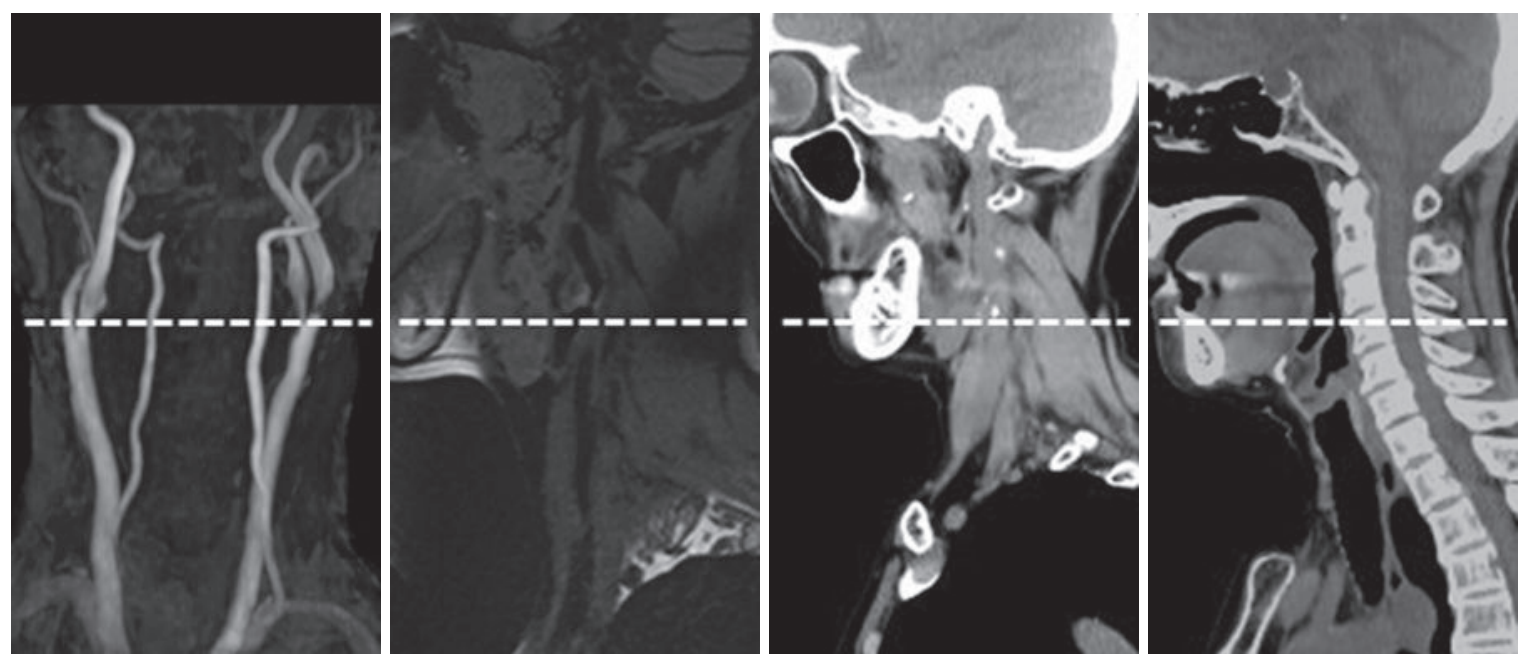

Fig. 4 Synchronized magnetic resonance (MR) angiogram (A), fat-suppressed T1-

$\mathbf{A}|\mathbf{B}| \mathbf{C} \mid \mathbf{D}$ weighted MR image (B), plain computed tomography (CT) image (C), and plain CT midsagittal image (D) showing a carotid bifurcation at the C4 level (white broken line) and distal end of the plaque at the C3 level. 


\begin{abstract}
結語
ヨードまたはヨード造影剂検査が不適応の症候性脳血管 障害患者に対し，造影剂を使用せずに術前評価を行い，直 達手術を施行した症例を経験したので, 若干の文献的考察 を加え報告した，造影剂に過敏症の既往がある場合，造影 剤の使用に関しては, ベネフィットとリスクを勘案して造 影の要否を検討しなければならないが，可能な限り代替検 査を選択するべきである，高齢化社会に伴い，今後は造影 剤アレルギーに限らず，腎機能・肝機能・心機能の低下な どの全身合併症により造影剂検查が不適応の患者に対 し，外科的治療を選択する機会が増えると考えられる.
\end{abstract}

本論文の要旨は, 第 45 回日本脳卒中の外科学会 $(2016$ 年 4 月 14 日)において発表した。著者全員は日本脳神経外 科学会への COI 自己申告を完了しており，本論文の発表 に関して開示すべきCOI はありません.

\section{文献}

1) Amar AP, Larsen DW, Teitelbaum GP: Percutaneous carotid angioplasty and stenting with the use of Gadolinium in lieu of iodinated contrast medium: technical case report and review of the literature. Neurosurgery 49: 1262-1265, 2001

2) Brockow K, Christiansen C, Kanny G, et al: Management of hypersensitivity reactions to iodinated contrast media. Allergy 60: 150-158, 2005

3) Burry MV, Cohen J, Mericle RA: Use of gadolinium as an intraarterial contrast agent for pediatric neuroendovascular procedures. J Neurosurg 100(2 Suppl Pediatrics): 150-155, 2004

4) Christiansen C: X-ray contrast media-an overview. Toxicology 209: 185-187, 2005

5) European Society of Urogenital Radiology: ESUR Guidelines on Contrast Media. v-9.0, 2014 (http://www.esur.org/guidelines/)

6) FDA Public Health Advisory: Gadolinium-containing contrast agents for Magnetic Resonance Imaging(MRI): Omniscan, OptiMARK, Magnevist, ProHance, and MultiHance(http:// www.fda.gov/cder/drug/advisory/gadolinium_agents_ 20061222.html)

7）伊藤 守, 細見晃一, 出原 誠, ほか：IVUS 主導による 造影剤を使用しない䪹動脈ステント留置術. 脳外速報 15 : 865-870, 2005

8) Katayama H, Yamaguchi K, Kozuka T, et al: Adverse reactions to ionic and nonionic contrast media: A report from Japanese committee on the safety of contrast media. Radiology 175: 621-628, 1990

9）松原巧明, 宮地茂, 泉 孝嗣, ほか：ヨードアレルギー患 者に Gadolinium 造影剂を用いて頚動脈ステント留置術を 行った 1 例. 脳外速報 18: 93-99, 2008

10) Morcos SK, Thomsen HS: Adverse reactions to iodinated contrast media. Eur Radiol 11: 1267-1275, 2001

11) Sakakibara M, Tsutsui H: Successful non contrast percutaneous coronary intervention for patient with unstable angina and prior anaphylactic reaction to iodinated contrast medium. Intern Med 48: 1753-1757, 2009

12) Slaba S, Abi Khalil S, Nassar J, et al: Gadolinium-medium filter-protected percutaneous stended carotid angioplasty. $J$ Mal Vasc 29: 165-167, 2004

13) Spinosa DJ, Kaufmann JA, Hartwell GD: Gadolinium chelates in angiography and interventional radiology: a useful alternative to iodinated contrast media for angiography. Radiology 223: $319-325,2002$ 